\title{
PRODUÇÃO DE SÍNTER DE MINÉRIO DE FERRO UTILIZANDO POEIRA DE ACIARIA ELÉTRICA COMO MATÉRIA PRIMA
}

\author{
Victor Bridi Telles ' \\ Denise Crocce Romano Espinosa ${ }^{2}$ \\ Jorge Alberto Soares Tenório ${ }^{3}$
}

\begin{abstract}
Resumo
A produção de aço através dos fornos elétricos a arco (FEA) gera aproximadamente $15 \%$ a $20 \%$ de poeira de aciaria elétrica (PAE). Este resíduo é considerado perigoso devido à presença de metais como o chumbo e o cádmio que lixiviam em água. Devido a isto, a reciclagem da PAE torna-se uma alternativa para diminuir custos com aterros além de diminuir os danos causados pelo resíduo no meio ambiente. Por sua vez, a sinterização de minério de ferro é um processo que reaproveita a maior parte dos finos gerados no setor siderúrgico. A PAE, contudo, não é reutilizada neste processo por conter zinco potencialmente contaminante ao sínter. $O$ zinco é altamente prejudicial no interior dos altos fornos, pois forma crostas no revestimento refratário e afeta o equilíbrio termodinâmico do processo. Deste modo, este trabalho estuda o reaproveitamento da PAE no processo de sinterização com o objetivo de produzir sínter de minério de ferro com teor de zinco dentro ou próximo do limite estabelecido para os altos fornos.
\end{abstract}

Palavras-chave: Poeira de aciaria; Resíduo industrial; Sinterização; Zinco.

\section{IRON ORE SINTER PRODUCTION USING ELECTRIC ARC FURNACE DUST AS RAW MATERIAL}

\begin{abstract}
The steel production through Electric Arc Furnaces (EAF) generates approximately 15\% to $20 \%$ of Electric Arc Furnace Dust (EAFD). This waste is considered dangerous due to the presence of metals as lead and cadmium that leach in contact with water. Because of this, the EAFD recycling becomes an alternative to diminish the costs with landfills and environmental harms caused by the waste. The iron ore sintering is a process that reuses most part of powders generated by the steelmaking. However the EAFD is not reused in this process because it contains zinc. The zinc is highly detrimental inside blast furnaces causing heavy crusts and affecting the thermodynamic equilibrium of the process. Therefore, this work studies the EAFD reuse in the iron ore sintering process to produce iron ore sinter with zinc contents between the limits established for blast furnaces.
\end{abstract}

Key words: Sintering dusts; Industrial waste; Sintering; Zinc.

'Doutorando em Engenharia Metalúrgica, Universidade de São Paulo - USP, Av. Professor Mello Moraes, 2463, Cep 05508-030,

Cidade Universitária, São Paulo, SP, Brasil. E-mail: bridi.victor@gmail.com

${ }^{2}$ Professora Associada, Doutora em Engenharia Metalúrgica, Universidade de São Paulo - USP, Av. Professor Mello Moraes, 2463, Cep 05508-030,

Cidade Universitária, São Paulo, SP, Brasil. E-mail: espinosa@usp.br

${ }^{3}$ Professor titular, Doutor em Engenharia Metalúrgica, Universidade de São Paulo - USP, Av. Professor Mello Moraes, 2463, Cep 05508-030,

Cidade Universitária, São Paulo, SP, Brasil. E-mail: jtenorio@usp.br 


\section{INTRODUÇÃO}

A sinterização de minério de ferro é empregada no setor metalúrgico para transformar finos de minério, através da aglomeração a quente junto com outras matérias primas, em um produto denominado sínter. $\mathrm{O}$ sínter é a principal fonte metálica empregada nos altos-fornos brasileiros. As principais matérias primas empregadas na sinterização além do minério de ferro são: coque (combustível), calcário (fundente) e rejeitos externos ou internos (sínter de retorno, fora das especificações granulométricas).

Pós e finos representam aproximadamente 13\% do total de resíduos gerados no setor siderúrgico. Dentre estes está a poeira de aciaria elétrica (PAE), um resíduo sólido coletado em sistemas de despoeiramento de fornos elétricos a arco (FEA).(1)

Dependendo do tipo de sucata utilizada no processo e do tipo de aço produzido, a PAE pode conter quantidades significativas de zinco, chumbo, cádmio, cromo e outros metais. Assim, se o resíduo for descartado sem o devido controle podem ocorrer contaminações dos lençóis freáticos causando sérios danos ao meio ambiente..$^{(2,3)}$

No Brasil foram produzidas 32,9 milhões de toneladas de aço bruto no ano de 2010 , neste mesmo ano cerca de $29 \%$ do aço produzido no mundo foi obtido via $\mathrm{FEA}$. Em alguns países a produção de aço através do FEA também está crescendo, nos Estados Unidos (EUA) a participação deste processo na fabricação do aço foi de $61,3 \%$ no ano de 2010 , enquanto que no ano 2000 este índice era de 47,0\%.(4)

Do mesmo modo em que a legislação ambiental torna-se mais rigorosa os custos para o descarte da PAE crescem, além disso, as indústrias enfrentam mais dificuldades para encontrar áreas destinadas aos aterros. Mediante a situação, as siderúrgicas procuram alternativas para reaproveitar este resíduo.

O reaproveitamento da PAE é interessante nos processos siderúrgicos tendo em vista o seu teor de ferro. Contudo a presença de zinco no interior do alto-forno é indesejável, uma parte do óxido de zinco pode se depositar nas paredes da cuba e nos condutores de saída de gases, interrompendo o seu fluxo, outra parte dos vapores pode formar incrustações no revestimento refratário do alto-forno. (2)

Com isso, o objetivo deste trabalho é utilizar a PAE na sinterização de minério de ferro e avaliar a melhor condição de aglomeração do resíduo com moinha de coque para a produção de um sínter com menor teor de zinco possível.

\section{MATERIAIS E MÉTODOS}

As principais etapas envolvidas neste trabalho foram (Figura I):

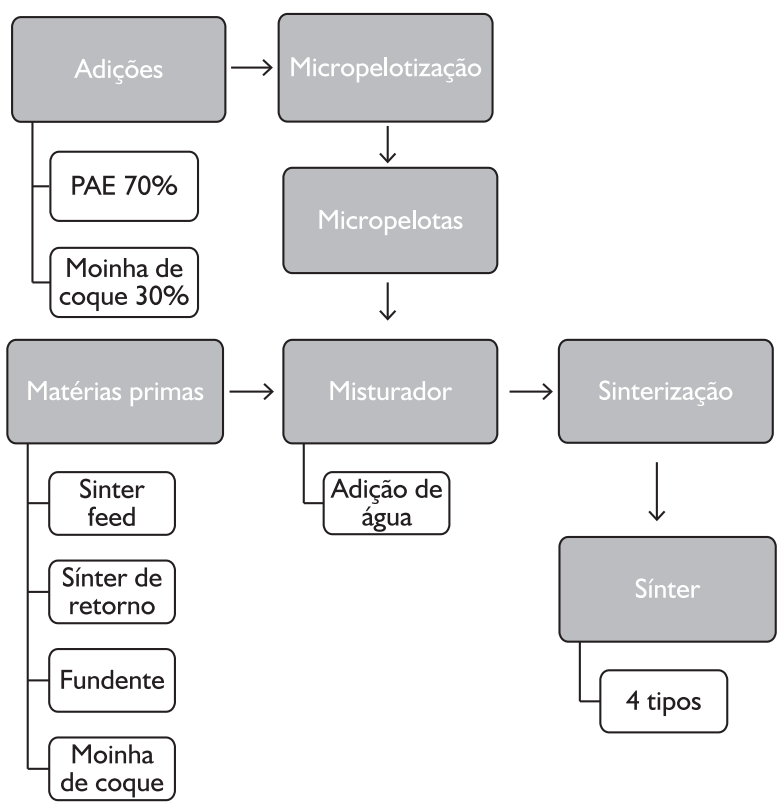

Figura I. Fluxograma dos materiais e métodos aplicados na produção do sínter.

- Análise química e granulométrica do resíduo (PAE);

- Fabricação de micropelotas (aglomerados com $3 \mathrm{~mm}$ a $5 \mathrm{~mm}$ de diâmetro) compostas por PAE (70\%) e moinha de coque (30\%);

- Produção das misturas de sinterização;

- Sinterização das misturas de referência e dos sínteres com adições de $10 \%$, $15 \%$ e $20 \%$ de micropelotas; e

- Caracterização das misturas e dos sínteres.

\section{I Caracterização da PAE}

Foram realizadas análises químicas por fluorescência de raios-X e por titulometria, para determinar os principais constituintes da amostra e $o$ teor de ferro metálico. O resíduo também foi caracterizado através de análise granulométrica utilizando o equipamento Malvern Mastersizer 2000.

\subsection{Fabricação das Micropelotas}

O minério de ferro para sinterização (sinter feed) deve possuir granulometria acima de $0,10 \mathrm{~mm}$ (150 mesh). Partículas com tamanhos menores diminuem a permeabilidade do leito de sinterização e prejudicam a produtividade do processo. ${ }^{(5)}$ Deste modo, o resíduo foi submetido a uma etapa de pré-aglomeração denominado micropelotização.

Uma mistura com $70 \%$ de PAE e $30 \%$ de moinha de coque foi micropelotizada separadamente em um misturador cilíndrico. As micropelotas com $3 \mathrm{~mm}$ a $5 \mathrm{~mm}$ de 
diâmetro foram classificadas por peneiramento e secas em estufa a $120^{\circ} \mathrm{C}$ durante 24 horas. Não foi utilizado qualquer tipo de aglomerante no processo de pré-aglomeração.

$O$ zinco é encontrado na PAE principalmente na forma $\mathrm{ZnO}$ (zincita) e $\mathrm{ZnFe}_{2} \mathrm{O}_{4}$ (franklinita). A inclusão da moinha de coque na composição das micropelotas teve por objetivo favorecer as reações de redução dos óxidos de zinco durante a sinterização. Após ser reduzido, o zinco na forma de vapor pode ser eliminado no processo de sinterização junto com os gases de saída.

As reações de redução ocorrem mais rapidamente com maiores quantidades de carbono, por outro lado o aumento de carbono diminui a resistência dos aglomerados. Deste modo, foi feito um teste preliminar fabricando micropelotas com diferentes proporções de PAE e moinha de coque $(20 \%, 30 \%, 40 \%$ e $50 \%$ de redutor). Em seguida, estas micropelotas foram levadas ao misturador cilíndrico junto com minério de ferro para verificar a resistência das mesmas durante a mistura.

\subsection{Processo de Sinterização}

Foi fabricada uma mistura de referência composta por $67 \%$ de minério de ferro (sinter feed), $24 \%$ de sínter de retorno (sínter fora das especificações granulométricas), $6 \%$ de moinha de coque e $3 \%$ de calcário. Sobre a mistura seca foi adicionado $5,5 \%$ de água. Esta mistura foi sinterizada originando o sínter de referência (sem adição de micropelotas). Além disso, foram realizadas outras sinterizações adicionando $10 \%, 15 \%$ e $20 \%$ de micropelotas sobre a mistura de referência. $O$ processo foi realizado em um sinterizador do tipo intermitente desenvolvido por Takano, ${ }^{(6)}$ mostrado na Figura 2 . Em cada teste foram sinterizados $9 \mathrm{~kg}$ de mistura. Optou-se em trabalhar com cerca de $75 \%$ da capacidade do sinterizador, o que corresponde a uma altura aproximada de $30 \mathrm{~cm}$ do leito de sinterização. A capacidade da câmara de sinterização não foi utilizada totalmente para aumentar o fluxo de ar que atravessa o leito e diminuir a quantidade de material utilizado nas experiências.

\subsection{Caracterização das Misturas e do Sínter}

As misturas úmidas e os produtos da sinterização foram caracterizados por espectrofotometria de absorção atômica para determinar o teor de zinco. Através dos resultados desta técnica, foi possível avaliar a quantidade de zinco eliminado durante o processo de sinterização.

\section{RESULTADOS E DISCUSSÃO}

\section{I Caracterização da PAE}

Através da técnica de fluorescência de raios- $X$, foram encontrados na PAE principalmente $\mathrm{Fe}(58,3 \%)$ e $\mathrm{Zn}(14,2 \%)$, a amostra apresentou também $\mathrm{Cr}(0,2 \%)$ e $\mathrm{Ni}(<0,05)$. Pode-se afirmar que o resíduo é proveniente da fabricação de aços planos e longos, pois a PAE obtida na fabricação de aços inoxidáveis possui concentrações menores de zinco e maiores teores de cromo e níquel. (7) Os resultados da titulometria mostraram que $0,6 \%$ do ferro está presente na forma metálica.

A composição química da PAE depende principalmente do tipo da carga, além do tipo e quantidade de aditivos que fazem parte do processo siderúrgico. Os resultados da Tabela I mostram que o resíduo é composto principalmente de $\mathrm{Fe}(58,3 \%)$ e $\mathrm{Zn}(\mathrm{I} 4,2 \%)$. Além disso, as quantidades de $\mathrm{Cr}$ e $\mathrm{Ni}$ indicam que a PAE é proveniente da fabricação de aços planos e longos, uma vez que poeiras oriundas da fabricação de aços inoxidáveis possuem maiores quantidades desses elementos.

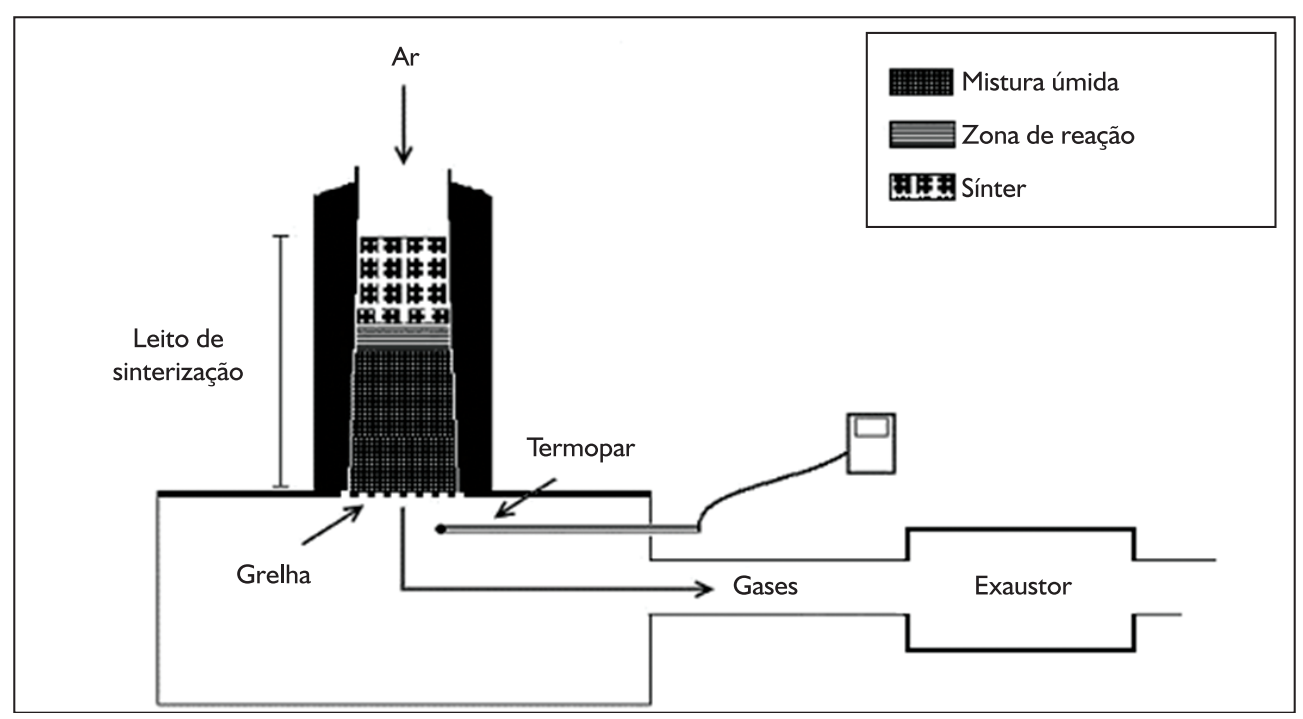

Figura 2. Esquema do sinterizador utilizado. 
O Fe é citado como ferro total, pois pode ser encontrado na PAE como wustita ( $\mathrm{FeO})$, hematita $\left(\mathrm{Fe}_{2} \mathrm{O}_{3}\right)$, magnetita $\left(\mathrm{Fe}_{3} \mathrm{O}_{4}\right)$ e ferro metálico. $\mathrm{O}$ zinco também está na forma total, pois além de $\mathrm{Zn}$ metálico, podem estar presentes no resíduo zincita $(\mathrm{ZnO})$ e franklinita $\left(\mathrm{ZnFe}_{2} \mathrm{O}_{4}\right)$. Alguns metais voláteis foram identificados $(\mathrm{Zn}, \mathrm{Pb}, \mathrm{K}, \mathrm{Cl})$, assim como elementos residuais $(\mathrm{Co}, \mathrm{Ni}$, $\mathrm{Sr}, \mathrm{Zr}, \mathrm{Sn}, \mathrm{Br}$ ) e também componentes de fusão de escória (Al, Mg, Ti). ${ }^{(8)}$ Geralmente, as substâncias que contêm cloro são provenientes da pintura das sucatas. A presença de $\mathrm{SiO}_{2}$ normalmente provém do arraste de componentes de escória ou refratários presentes na produção do aço. ${ }^{(7)}$ A composição química do resíduo estudado neste trabalho está próxima dos valores encontrados em outros estudos. ${ }^{(9-12)}$

A Tabela 2 mostra os resultados da análise granulométrica do resíduo. Os resultados mostraram que a PAE é um resíduo fino, no qual $90 \%$ das partículas possuem tamanho menor que $8,21 \mu \mathrm{m}$.

O maior diâmetro de partícula detectado pelo equipamento foi de $76,32 \mu \mathrm{m}(0,076 \mathrm{~mm})$. Este valor está abaixo do limite máximo nas especificações de pellet feed $(0,149 \mathrm{~mm})$. Portanto, nesse aspecto, a PAE é um resíduo que pode ser utilizado em processos de pelotização, entretanto apresenta granulometria muito fina para ser usada diretamente em processos de sinterização, necessitando uma aglomeração prévia. Esta granulometria do material está de acordo com outras pesquisas. ${ }^{(13-16)}$

Tabela I. Composição química da PAE (porcentagem em massa)

\begin{tabular}{cc}
\hline Componentes & $\%$ \\
\hline $\mathrm{Fe}_{\text {total }}$ & 58,3 \\
$\mathrm{Fe}_{\text {metalico }}$ & 0,6 \\
$\mathrm{Zn}_{\text {total }}$ & 14,2 \\
$\mathrm{CaO}$ & 4,7 \\
$\mathrm{SiO}_{2}$ & 4,18 \\
$\mathrm{MnO}$ & 2,05 \\
$\mathrm{MgO}$ & $\mathrm{I}, 52$ \\
$\mathrm{PbO}$ & $\mathrm{I}, 18$ \\
$\mathrm{Al}_{2} \mathrm{O}_{3}$ & 0,68 \\
$\mathrm{Cr}_{2} \mathrm{O}_{3}$ & 0,2 \\
$\mathrm{NiO}$ & $<0,05$ \\
$\mathrm{Outros}$ & 12,9 \\
\hline
\end{tabular}

Tabela 2. Distribuição do tamanho das partículas da PAE

\begin{tabular}{cccc}
\hline $\begin{array}{c}\text { Tamanho } \\
(\mu \mathrm{m})\end{array}$ & (\%) & $\begin{array}{c}\text { Tamanho } \\
(\mu \mathrm{m})\end{array}$ & (\%) \\
\hline$<76,32$ & 100 & $<1,95$ & 54,32 \\
$<35,56$ & 98,78 & $<1,78$ & 50 \\
$<10,48$ & 91,97 & $<1,06$ & 25,95 \\
$<8,21$ & 90 & $<0,67$ & 10 \\
$<6,63$ & 87,97 & $<0,49$ & 4,19 \\
$<3,09$ & 72,85 & $<0,36$ & 0,99 \\
\hline
\end{tabular}

\subsection{Pré-aglomeração}

Os testes preliminares utilizando $20 \%, 30 \%$, $40 \%$ e $50 \%$ de redutor indicaram que o aumento da quantidade de moinha de coque diminui a resistência dos aglomerados. Foi fixado o teor de $30 \%$ de moinha de coque na composição das micropelotas, uma vez que nesta proporção os aglomerados apresentaram resistência suficiente para serem submetidos à etapa de mistura antes da sinterização (micropelotização) sem se romper.

\subsection{Eliminação do Zinco}

O tempo de sinterização foi de nove minutos para o teste de referência e II minutos para os testes com adições. Uma vez que as adições possuíam moinha de coque na sua composição, este reagiu em maior proporção na mistura, aumentando o tempo de sinterização.

Os resultados da espectrofotometria de absorção atômica podem ser vistos na Tabela 3 .

O sínter de referência apresentou quantidades residuais de zinco $(0,02 \%)$. Este valor é maior se comparado com o encontrado na mistura de referência $(0,006)$, porém está dentro do erro da análise $( \pm 0,05 \%)$. Apesar de ser indesejável nos altos-fornos, o zinco é encontrado em baixas concentrações nos sínteres devido às impurezas dos minérios de ferro.

A reação geral da redução carbotérmica da franklinita e da zincita podem ser observadas na Equação I e na Equação 2, respectivamente: ${ }^{(17,18)}$

$$
\begin{aligned}
& \mathrm{ZnFe}_{2} \mathrm{O}_{4(\mathrm{~s})}+4 \mathrm{C}_{(\mathrm{s})} \leftrightarrow \mathrm{Zn}_{(\mathrm{g})}+2 \mathrm{Fe}_{(\mathrm{s})}+4 \mathrm{CO}_{(\mathrm{g})} \\
& \mathrm{ZnO}_{(\mathrm{s})}+\mathrm{C}_{(\mathrm{s})} \leftrightarrow \mathrm{Zn}_{(\mathrm{g})}+\mathrm{CO}_{(\mathrm{g})}
\end{aligned}
$$

A redução destes óxidos ocorre a partir de $900^{\circ} \mathrm{C}$ (próximo do ponto de ebulição do zinco), sendo que a cinética de redução é ainda maior acima de $1.050^{\circ} \mathrm{C}$. Portanto, estas reações ocorreram na zona de reação e continuaram até os momentos iniciais do resfriamento do sínter (aproximadamente $910^{\circ} \mathrm{C}$ ). Em temperaturas inferiores (abaixo de $900^{\circ} \mathrm{C}$ ), o ambiente oxidante predomina no leito de sinterização e o zinco é reoxidado.

Parte do zinco, proveniente da PAE, foi eliminada do sistema junto com os gases de saída. Porém, uma parte restante ficou na composição do sínter, pois não houve tempo suficiente para que o metal (na forma de vapor) fosse arrastado junto com os outros gases.

Tabela 3. Teor de zinco presente nas amostras

\begin{tabular}{ccc}
\hline Adições (\%) & $\begin{array}{c}\text { Teor de Zn (\%) } \\
\text { mistura }\end{array}$ & $\begin{array}{c}\text { Teor de Zn (\%) } \\
\text { sínter }\end{array}$ \\
\hline- & 0,006 & 0,02 \\
10 & 1,3 & 0,10 \\
15 & 1,7 & 0,93 \\
20 & 2,1 & 1,8 \\
\hline
\end{tabular}




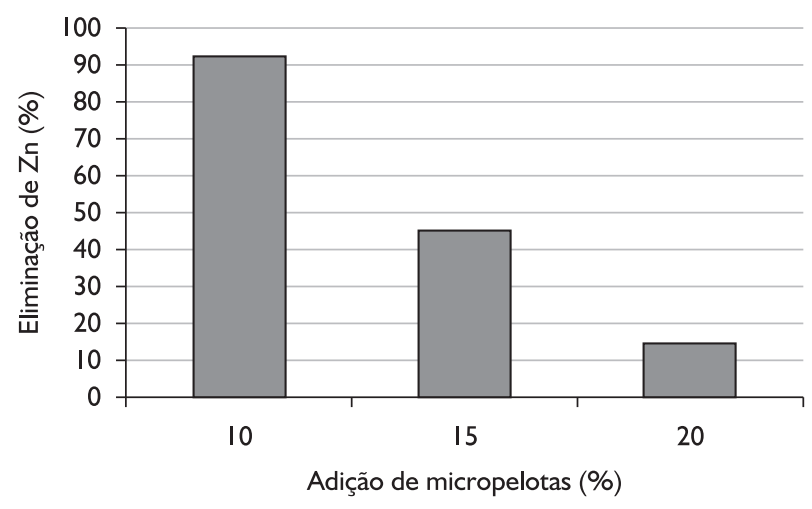

Figura 3. Eliminação de zinco em função do percentual de micropelotas.

Contudo, com 10\% de micropelotas na mistura de sinterização foi possível produzir um sínter com baixo teor de zinco $(0,1 \%)$. A quantidade de zinco que entra no alto-forno, geralmente, varia entre $0,15 \mathrm{~kg}$ e $0,5 \mathrm{~kg}$ por tonelada de ferro gusa ou $0,1 \%$ da carga. Na França, o valor máximo de zinco no alto forno é de $0,15 \mathrm{~kg}$ por tonelada de ferro gusa, no Reino Unido o limite é de $0,5 \mathrm{~kg} / \mathrm{t}$ e nos Estados Unidos a quantidade de zinco permitido no processo varia entre $0,5 \mathrm{~kg}$ e I, $0 \mathrm{~kg}$ para cada tonelada de ferro gusa produzido.(16)

A Figura 3, baseada nos resultados da análise química, mostra a eliminação de zinco das amostras que receberam adição do resíduo.

Através da Figura 3 pode-se observar que, com o aumento da adição de micropelotas na mistura de sinterização houve um aumento do teor de zinco nos sínteres, ou seja, houve uma diminuição da eliminação do zinco.

A relação de moinha de coque/resíduo foi de I,2 para a mistura com 10\%, 0,91 para a mistura com 15\% e 0,77 para a mistura com adição de $20 \%$ de micropelotas. Quanto maior a proporção de redutor (moinha de coque) sobre os óxidos de zinco (presentes na PAE), mais veloz é a cinética de redução. ${ }^{(17)}$ Deste modo, a eliminação de zinco foi maior na sinterização com maior relação coque/resíduo (92,3\% com $10 \%$ de micropelotas). $\mathrm{Na}$ sinterização da mistura com $15 \%$ de micropelotas foi eliminado $45,3 \%$ de zinco e para $20 \%$ de micropelotas foi eliminado $14,3 \%$ do metal.

\section{CONCLUSÕES}

A PAE é um resíduo fino ( $90 \%$ abaixo de $8,21 \mu \mathrm{m}$ ) que não necessita de ser submetida a um processo de moagem. Porém o resíduo deve ser pré-aglomerado para não diminuir a permeabilidade do leito de sinterização e atender as especificações granulométricas do processo. O aumento do teor de moinha diminui a resistência das micropelotas, de modo que valores maiores que 30\% inviabilizaram a fabricação do aglomerado.

Este trabalho mostra que é possível produzir sínter de minério de ferro com baixo teor de zinco utilizando PAE na mistura de sinterização. Com $10 \%$ de micropelotas adicionadas na mistura de sinterização foi obtido um sínter com $0,1 \%$ de zinco. Este valor está dentro do limite estabelecido pelas indústrias. Contudo, a quantidade de zinco no interior do alto-forno pode ser ainda menor mediante a implantação de um sistema de carregamento que permita a inclusão de sínter produzido com e sem reciclagem do resíduo.

Os resultados também mostraram que a eliminação de zinco durante a sinterização é maior em misturas mais ricas em carbono. $O$ zinco eliminado durante a sinterização pode ser coletado em sistemas de limpeza de gases. Deste modo, esta nova poeira poderia, possivelmente, ser utilizada em processos hidro e pirometalúrgicos se o teor de zinco for suficientemente alto $(20 \%$ a $25 \%$, dependendo do processo de recuperação), ou ser novamente reciclada no processo de sinterização.

A reutilização da PAE no processo de sinterização pode ainda trazer benefícios ambientais e econômicos, uma vez que o resíduo deixaria de ser disposto em aterros sanitários.

\section{Agradecimentos}

Os autores agradecem à Capes pela concessão da bolsa referente ao período da pesquisa e à Universidade de São Paulo (USP).

\section{REFERÊNCIAS}

I INSTITUTO BRASILEIRO DE SIDERURGIA. Relatório de sustentabilidade 2008. Disponível em: <http://www.ibs. org.br/publicacoes.asp >. Acesso em: 20 jan. 2009.

2 MANTOVANI, M. C. Caracterização de poeiras geradas em forno elétrico a arco e seu estudo quando aglomeradas na forma de pelotas auto-redutoras. 1998. 165 f. Tese (Doutorado) - Escola Politécnica da Universidade de São Paulo, São Paulo, 1998.

3 DONALD, J. R.; PICKLES, C. A. Reduction of electric arc furnace dust with solid iron powder. Canadian Metallurgical Quarterly, v. 35, n. 3, p. 255-67, July-Sept. 1996. 
4 WORLDSTEEL ASSOCIATION. Steel statistical yearbook 20 I I. Disponível em: <http://www.worldsteel.org/index. php?action= publicationdetail\&id=97>. Acesso em: 16 mar. 2010.

5 SILVA, G. F. B. L. Reciclagem de resíduos siderúrgicos sólidos contendo ferro via tecnologia de aglomeração através da solução de um modelo multicriterial hierárquico e de programação linear. 2004. 2 I If. Tese (Doutorado) - Escola Politécnica da Universidade de São Paulo, São Paulo, 2004.

6 TAKANO, C. Estudo da influência de alguns combustíveis na sinterização de minério de ferro. 1970. 101 p. Tese (Doutorado) - Escola Politécnica, Universidade de São Paulo, São Paulo, 1970.

7 SILVA, M. et al. Characterisation of electric arc furnace dust generated during plain carbon steel production. Ironmaking and Steelmaking, v. 35, n. 4, p. 315-320, May 2008. http://dx.doi.org/10.1 I 79/030192307X232936

8 HUBER, J et al. Some means to reduce emissions and improve the recovery of electric arc furnace dust by controlling the formation mechanisms. Proceedings of the Rewas '99: Global Symposium on Recycling, Waste Treatment and Clean Technology. San Sebastián, p. I483-I49I, 1999.

9 MACHADO, J. G. M. S. Estudo da caracterização e avaliação da influência do tempo na redução carbotérmica do pó de aciaria elétrica. 2004. 94f . Dissertação (Mestrado) - Programa de Pós-Graduação em Eng Minas, Metalúrgica e Materiais, Universidade Federal do Rio Grande do Sul, Porto Alegre, 2004.

I0 VARGAS, A. S.; MASUERO, A. B.; VILELA, A. C. F. Estudo microestrutural e determinação do calor de hidratação em pastas de cimento Portland com pó de aciaria elétrica (PAE). Ambiente Construído, v. 4, n. 2, p. 7-I8, 2004.

II BREHM, F. A. Adição de óxido de zinco ( $\mathrm{ZnO}$ e em pastas de cimento portland visando viabilizar a reciclagem de pós de aciaria elétrica (PAE) na construção civil. 2004. 90 f. Tese (Pós-Doutorado) - Universidade Federal do Rio Grande do Sul, Porto Alegre, 2004.

I2 BREHM, F. A. et al. Characterization and use of eaf dust in construction. In: JAPAN-BRAZIL SYMPOSIUM ON DUST PROCESSING- ENERGY ENVIRONMENT IN METALLURGICAL AND MATERIALS ENGINEERING, 3., 200I, São Paulo. Proceedings... São Paulo: USP, 200I. p. I73-I80.

I3 MANTOVANI, M. C.; TAKANO, C.; CAVALLANTE, F. L. Caracterização de três tipos de poeiras geradas em fornos elétricos a arco. In: CONGRESSO ANUAL DA ABM, 53., 1998, Belo Horizonte. Anais... São Paulo: ABM, 1998. p. I329-1343.

14 MANTOVANI, M. C.; TAKANO, C.; BÜCHLER, P. M. EAF and secondary dust characterization. Ironmaking and Steelmaking, v. 3I, n. 4, p. 325-332, Aug. 2004. http://dx.doi.org/I0.II 79/030I923042250I8I63

I5 NOLASCO SOBRINHO, P. J.; ESPINOSA, D. C. R.; TENÓRIO, J. A. S. Characterisation of dusts and sludges generated during stainless steel production in Brazilian industries. Ironmaking and Steelmaking, v. 30, n. I, p. I I-I7, Feb. 2003. http://dx.doi.org/I0.1 I79/030192303225009506

I6 NOLASCO SOBRINHO, P. J.; ESPINOSA, D. C. R.; TENÓRIO, J. A. S. Caracterização da poeira gerada na fabricação de aço inoxidável visando à sua reciclagem. Revista da Escola de Minas, v. 53, n. 4, p. 257-263, abr.-jun. 2000.

17 ESEZOBOR, D. E.; BALOGUN, S. A. Zinc accumulation during recycling of iron oxide wastes in the blast furnace. Ironmaking and Steelmaking, v. 33, n. 5, p. 419-425, Oct. 2006. http://dx.doi.org/I 0. I I79/I 74328 I 06XI I 4020

18 JYH-JEN LEE, CHUN-I LIN, and HSI-KUEI CHEN. Carbothermal reduction of zinc ferrite. Metallurgical and Materials Transactions B, v. 32, n. 6, p. 1033-1040, Dec. 2001.

Recebido em: 15/06/2012

Aceito em: 18/02/2013 